\title{
Identification of verocytotoxin-producing Escherichia coli O117:H7 in men who have sex with men, England, November 2013 to August 2014
}

I Simms (ian.simms@phe.gov.uk)ㄹ, V L Gilbart¹, L Byrne², C Jenkins³, G K Adak², G Hughes¹, P D Crook ${ }^{4}$

1. HIV and STI Department, Public Health England Health Protection Services, Colindale, United Kingdom

2. Gastrointestinal, Emerging and Zoonotic Infections Department, Public Health England Health Protection Services, Colindale, United Kingdom

3. Gastrointestinal Bacteria Reference Unit, Public Health England Reference Microbiology Services, Colindale, United Kingdom 4. Public Health England Health Protection Field Epidemiology Services, London, United Kingdom

Simms I, Gilbart VL, Byrne L, Jenkins C, Adak GK, Hughes G, Crook PD. Identification of verocytotoxin-producing Escherichia coli O117: H7 in men who have sex with men, England, November 2013 to August 2014. Euro Surveill. 2014;19(43):pii=20946. Available online: http://www.eurosurveillance.org/ViewArticle. aspx?Articleld $=20946$

Article submitted on 06 October 2014 / published on 30 October 2014

Between November 2013 and August 2014, nine cases of verocytotoxin-producing Escherichia coli $0_{117}: \mathrm{H}_{7}$ VT1 were confirmed in adult men. Further investigation using semi-structured interviews revealed that eight cases were United Kingdom (UK)-born men who have sex with men (MSM) who had sexually acquired infection in the UK. Most were HIV-positive with high numbers of sexual partners. This behavioural profile resembles that associated with the recent rapid increase in other sexually acquired infections in MSM.
Few diagnoses of verocytotoxin-producing Escherichia coli (VTEC) 0117: $\mathrm{H}_{7} \mathrm{VTI}$ are reported each year in England. Between 1 January 2009 and 20 November 2013, Public Health England's (PHE) Gastrointestinal Bacteria Reference Unit (GBRU) confirmed just 13 cases of VTEC 0117: $\mathrm{H}_{7} \mathrm{VT}_{1}$ (Figure) compared with 4,050 cases of VTEC $\mathrm{O}_{157}$ in the same period. Travel history was available for 10 of the 13 cases and all reported recent travel to countries with a high prevalence of VTEC 0117: $\mathrm{H}_{7}[1,2]$.

\section{FIGURE}

Diagnoses of verocytotoxin-producing Escherichia coli O117:H7 VT1, by sex and history of travel abroad, England, 2009 to $2014(n=22)$

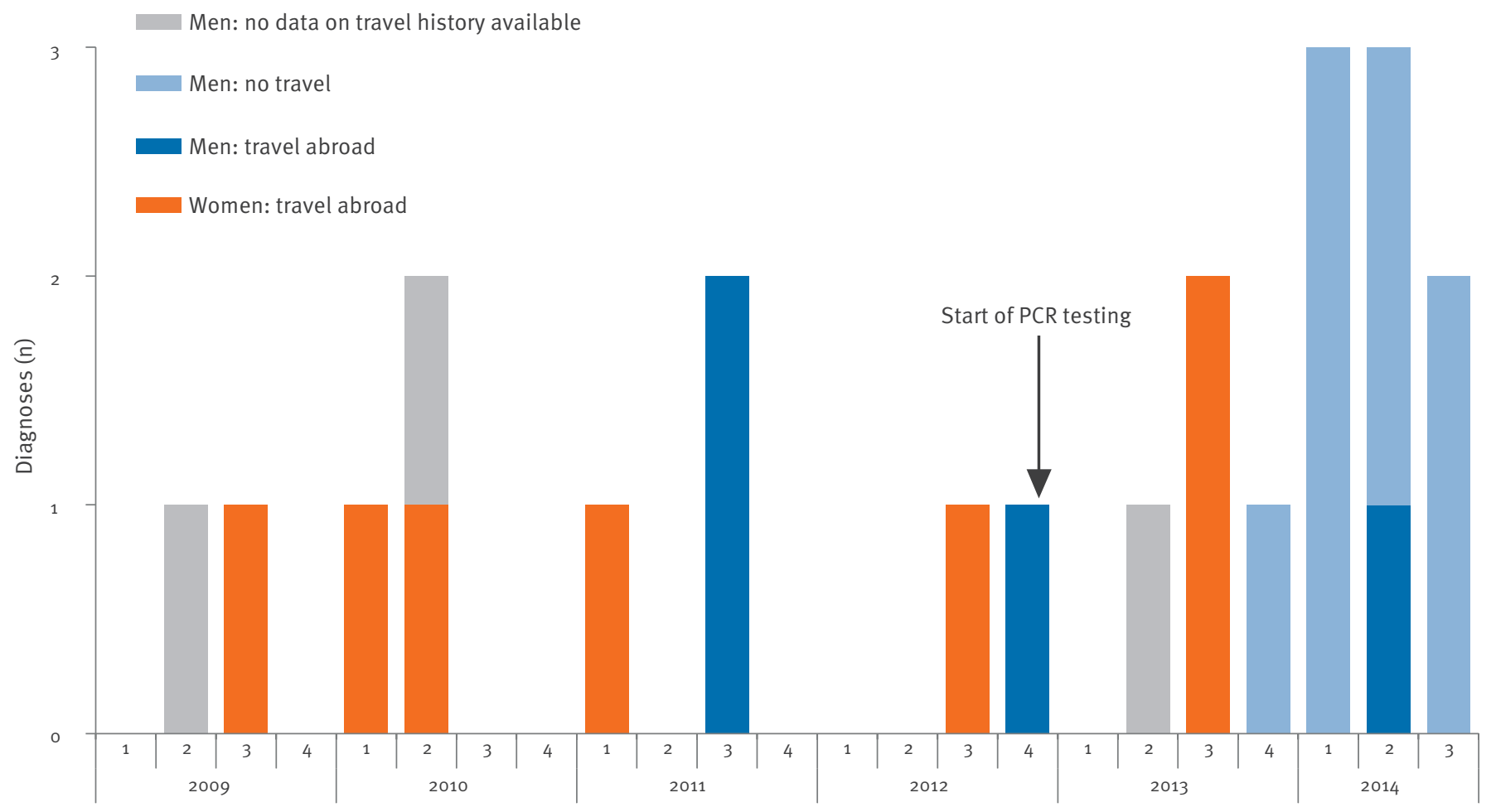


In June 2014, GBRU detected an increase in VTEC 0117: $\mathrm{H}_{7}$ VT1 diagnoses with nine cases confirmed since 21 November 2013 (Figure). All were adult men, of whom three were referred from genitourinary clinics and only one reported recent travel. An incident control team was established on 4 July 2014 to investigate this increase, the clinical presentation of cases and possible links with the ongoing Shigella flexneri za outbreak in men who have sex with men (MSM) [3-5].

\section{Incident investigation}

On 19 June, 204 laboratories in England were alerted to the increase in VTEC 0117: $\mathrm{H}_{7} \mathrm{VT}_{1}$ and asked to refer all presumptive $S$. sonnei isolates to the GBRU. Cases of reported VTEC infection were investigated in line with PHE standard operating procedures [6]. In addition to the routine enhanced surveillance questionnaire for VTEC, all men older than 18 years diagnosed with VTEC 0117:H7 VT1 after 1 November 2013 were invited to take part in confidential semi-structured face-to-face interviews with a sexual health advisor after patient consent had been obtained by the local Public Health Office. The interviews lasted 1.5 hours and explored the men's lifestyle and sexual behaviour, focusing on the two weeks before the onset of symptoms, i.e. the period within which infection had been acquired. Demographic data and information on sexual behaviour were collected, together with details of where they met sexual partners, recreational drug use, engagement with health services, previous history of sexually transmitted infections (STI) and testing for human immunodeficiency virus (HIV). For HIV-positive men, the most recent $\mathrm{CD}_{4} \mathrm{~T}$-cell count, viral load and current treatment regime were also discussed.

\section{Results}

Between 21 November 2013 and 21 August 2014, nine cases of VTEC 0117:H7 VT1 were identified, none of which had evident common food, water or animal exposures. One of them was a heterosexual man who had recently travelled to South America. The remaining eight were MSM, seven of whom consented to be interviewed. The median age of the seven men was 46 years (range: 33-50 years), most of whom (6/7) were of white ethnicity. Six men were in a relationship and three of whom cohabited with their male partner. All had open relationships and were reported from London and Brighton, cities that have large, vibrant gay communities.

In the two weeks before onset of illness, the seven men reported a median of five partners (range: $2-15$ ) and in the previous year, a median of 40 partners (range: 5-480). There was no evidence that any of the sexual contacts were cases. For the two weeks before onset, all seven men reported unprotected oral-anal contact with casual partners, they also reported receptive fisting (2/7), insertive fisting (3/7) and scat play $(1 / 7)$. Four men had met sexual partners through social media using geo-spatial networking applications that allow users to locate and meet men with similar sexual interests within close proximity. Two men had attended sex parties during that time. Three of the seven men reported chemsex, i.e. having sex under the influence of one or more of the following drugs: mephedrone, crystal methamphetamine (crystal meth), gammahydroxybutrate (GHB) and gamma-butyrolactone (GBL). These drugs, which are taken immediately before and/ or during sex, facilitate sexually disinhibiting behaviour and increased sex drive. Although the drugs can be injected, none of the men reported this practice [7].

Three men were HIV-positive and on therapy. A history of a range of STIs including lymphogranuloma venereum $(L G V)(n=3)$, gonorrhoea $(n=4)$, syphilis $(n=1)$ and chlamydia $(n=6)$ was reported within the past five years. All seven men had heard of $E$. coli but only three had seen the recent shigellosis information campaigns by PHE and Terrence Higgins Trust (www.tht.org.uk). Although one man experienced acute infection with bloody diarrhoea, others described more chronic illness with symptoms of mild stomach cramps and fatigue which generally lingered for several weeks, one man seeking medical advice after a month. The men sought medical advice from their general practitioner or genitourinary medicine clinic. One man was subsequently admitted to hospital.

\section{Discussion}

Initial findings from this ongoing investigation detail the first cluster of VTEC $0117: \mathrm{H}_{7} \mathrm{VT}_{1}$ to be described in MSM. There was no evidence that this was part of a generalised epidemic or that the observations were the result of sampling bias. VTEC 0117: 77 may be misidentified as $S$. sonnei by local diagnostic laboratories as there are similarities in colony appearance and biochemical profile. Such misidentifications are detected when strains are referred for confirmation and typing at the GBRU. Since December 2012, a small number of laboratories, including services in Brighton and central London have adopted polymerase chain reaction (PCR) techniques to detect verocytotoxin genes in stool samples, resulting in an increased number of diagnoses of non-0157 VTEC, including serogroup 0117 [3].

This strain does not possess the pathogenicity factor intimin and the stx2a shiga-toxin subtype which are known to be associated with more severe disease and progression to haemolytic-uraemic syndrome (HUS) [3]. Previous clusters have mainly been travel-associated and limited to around three cases [1]. Although the small sample size restricts interpretation, we have shown that recent diagnoses of VTEC $\mathrm{O}_{117}: \mathrm{H}_{7} \mathrm{VT}_{1}$ in England have been sexually acquired by highly sexually active MSM born in the United Kingdom, some of whom were HIV-positive and took chemsex drugs. This behavioural profile resembles that of LGV, infectious syphilis and shigellosis epidemics in England $[4,8,9]$. Such overlapping epidemics, sustained by closely related sexual networks facilitated by geospatial social networking applications, allow hyperefficient transmission, an environment in which infection 
control has been difficult to achieve. Infections have become endemic despite increased case finding and proactive campaigns (www.tht.org.uk/shigella) to raise awareness about Shigella and provide hygiene advice through advertisement in the gay press, magazines, leaflets in clinics and general practitioners' surgeries as well as pop-up banners on internet sites.

\section{Conclusion}

This new cluster further highlights the importance of enhancing and strengthening measures to decrease faecal-oral transmission of infection and increase awareness amongst MSM. This is of particular importance and a cause for concern should a more pathogenic VTEC be introduced into this high-risk group. The public health response to VTEC 0117: $\mathrm{H}_{7} \mathrm{VT}_{1}$ has been combined with ongoing initiatives aimed at improving the health and wellbeing of MSM and promoting access to health services [10].

\section{Acknowledgements}

We would like to thank the patients for their time and openness, health protection and environmental health colleagues, Fran McNeil (PHE Health Protection Services), Chris Lane (Department of Gastrointestinal, Emerging and Zoonotic Infections, PHE Health Protection Services) and Richard Scholey (Terrence Higgins Trust).

Conflict of interest

None declared.

\section{Authors' contributions}

All the authors contributed to the initiation of the project, designing the methods used as well as the data analysis and interpretation. All the authors contributed to writing the manuscript and have all read and agreed the final draft.

\section{References}

1. Olesen B, Jensen C, Olsen K, Fussing V, Gerner-Smidt P, Scheutz F. VTEC 0117:K1:H7. A new clonal group of E. coli associated with persistent diarrhoea in Danish travellers. Scand J Infect Dis. 2005;37(4):288-94. http://dx.doi. org/10.1080/00365540410021090 PMID:15804665 http:// dx.doi.org/10.1080/00365540410021090

2. Dallman T, Cross L, Bishop C, Perry N, Olesen B, Grant KA, et al. Whole genome sequencing of an unusual serotype of Shiga toxin-producing Escherichia coli. Emerg Infect Dis. 2013;19(8):1302-4. http://dx.doi.org/10.3201/eid1908.130016 PMID:23877005 http://dx.doi.org/10.3201/eid1908.130016

3. Byrne L, Vanstone GL, Perry NT, Launders N, Adak GK, Godbole G, et al. Epidemiology and microbiology of Shiga toxin-producing Escherichia coli other than serogroup 0157 in England, 2009-2013. J Med Microbiol. 2014;63(Pt 9):1181-8. http://dx.doi.org/10.1099/jmm.0.075895-0 PMID:24928216 http://dx.doi.org/10.1099/jmm.0.075895-0

4. Gilbart VL, Simms I, Gobin M, Oliver I, Hughes G. Highrisk drug practices in men who have sex with men. Lancet 2013;381(9875):1358-9. http://dx.doi.org/10.1016/S01406736(13)60882-X PMID:23601946 http://dx.doi.org/10.1016/ S0140-6736(13)60882-X

5. Borg ML, Modi A, Tostmann A, Gobin M, Cartwright J, Quigley C, et al. Ongoing outbreak of Shigella flexneri serotype $3 a$ in men who have sex with men in England and Wales, data from 2009-2011. Euro Surveill. 2012;17(13):20137. Available from: http://www.eurosurveillance.org/ViewArticle. aspx?Articleld=20137 PMID:22490381
6. Health Protection Agency (HPA). The VTEC Operational Manual. Operational guidance for HPA staff dealing with cases and incidents of VTEC infection. London: HPA; 2011. Available from: http://webarchive.nationalarchives. gov.uk/20140714084352/http://www.hpa.org.uk/webc/ HPAwebFile/HPAweb_C/1279889252950

7. Bourne A, Reid D, Hickson F, Torres Rueda S, Weatherburn P. The Chemsex Study: drug use in sexual settings among gay and bisexual men in Lambeth, Southwark \& Lewisham. London: Sigma Research, London School of Hygiene \& Tropical Medicine; 2014. ISBN 978-1-906673-19-2. Available from: http://www.sigmaresearch.org.uk/files/report2014a.pdf

8. Hughes G, Alexander S, Simms I, Conti S, Ward H, Powers C, et al.; LGV Incident Group. Lymphogranuloma venereum diagnoses among men who have sex with men in the U.K.: interpreting a cross-sectional study using an epidemic phasespecific framework. Sex Transm Infect. 2013;89(7):542-7. PMID:23851189

9. Jebbari H, Simms I, Conti S, Marongiu A, Hughes G, Ward H, et al. Variations in the epidemiology of primary, secondary and early latent syphilis, England and Wales: 1999 to 2008. Sex Transm Infect. 2011;87(3):191-8. http://dx.doi.org/10.1136/ sti.2009.040139 PMID:21262786 http://dx.doi.org/10.1136/ sti.2009.040139

10. Public Health England (PHE). Strategic Framework to Promote the Health and Wellbeing of Gay, Bisexual and other Men Who Have Sex with Men. London: PHE; 2014. Available from: https://www.gov.uk/government/uploads/system/uploads/ attachment_data/file/313692/Strategic_Framework_to promote_the_health_and_wellbeing_of_MSM_FINAL_DRAFT For comment.pdf 